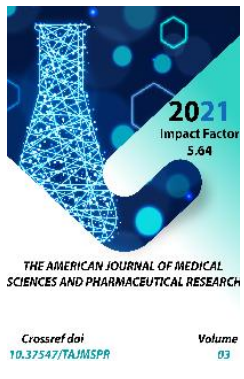

Copyright: Original content from this work may be used under the terms of the creative commons attributes 4.0 licence.

\section{Online Passage Of The Practical Lesson On The Topic" Fluid Flow And Biophysical Properties " In The Module System}

\author{
Muxiddin Xalimovich Jalilov \\ PhD On Physics' At The Samarkand Medical Institute, Uzbekistan \\ Xudoykulova Shoira Narzullayevna \\ High Assistant At The Samarkand Medical Institute, Uzbekistan \\ Ergashev Askar Jangoboyevich \\ Assistant At The Samarkand Medical Institute, Uzbekistan \\ Xusniddin Muxiddinovich Jalilov \\ Assistant At The Samarkand Medical Institute, Uzbekistan \\ Xalikulova Amina Qamariddnovna \\ 2 Course Student At The Samarkand Medical Institute, Uzbekistan
}

\title{
ABSTRACT
}

This article is devoted to the transition of "Fluid flow and biophysical properties" in a modular system. The importance of viscosity coefficient in medicine, its application in diagnosis and forensic medical examination is described. However, the Stokes method of finding the viscosity coefficient, the availability of viscometric methods, the application of Gess (VK-4) viscometer in medicine to find the viscosity coefficient are described.

\section{KEYWORDS}

Fluid, velocity, viscosity, modulus, internal friction coefficient, viscometer, hydraulic resistance, turbulent flow, "ZOOM" program, testing, video conferencing, Temperature dependence, diagnostics, independent mastering.

\section{INTRODUCTION}

The fluid environment makes up a large part of the human body ( $\approx 70 \%$ ) (blood, lymph, urine, breast milk, etc.) The movement of fluids throughout the body provides metabolism and cells with nutrients and oxygen. Releases nutrient residues and carbon dioxide from cells. Therefore, fluids flow throughout the body and the biophysical properties need to be 
known to medical institute students and medical staff. This topic is devoted to the study of the rheological sections of physics and the coefficient of viscosity of blood and its measurement methods.

Training at the Samarkand State Medical Institute (SamDTI) has been conducted in a modular system since 2013. To date, more than six and a half terabytes of data have been collected on the basis of the modular system of the institute platform. According to the State Educational Standards and the decision of the "Pedagogical Council" of the Institute of August 14, 2020, 18 hours of lectures, 54 hours of practical classes and 36 hours of independent work are allocated for the subject "Medical and Biological Physics" [1.2].

Given the current prevalence of the Coronavirus pandemic around the world and the high prevalence of various infectious diseases in some countries, we will explain the benefits of teaching in the modular system of the SamMI platform during the passage on "Fluid flow and biophysical properties."

80 minutes are allocated for a practical lesson on "Fluid flow and biophysical properties." It is called "Methods for finding the coefficient of internal friction of liquids." The purpose of writing this article is to cover in detail the practical lesson on the platform SamMI, modular system, online in the program "ZOOM" and "telegram".

I. Time distribution of the practical lesson on "Methods for finding the coefficient of internal friction of liquids."

1. Organizational part of the lesson ( $5 \mathrm{~min}$.).

2. Principles of operation of tools and equipment required for laboratory work. (10 min.).
3. Information on the "coefficient of internal friction of liquids" (15 min.).

4. Theoretical data on the determination of the "coefficient of viscosity of liquids" by the Stokes method (10 min.).

5. Theoretical information on the determination of the "coefficient of internal friction of liquids" by the Ostvold method (15 min.).

6. Using a medical viscometer (Gess), determine the coefficient of internal friction of liquids (10 min.).

7. Application of "coefficient of internal friction of liquids" in medicine (10 min.).

8. Concluding part of the lesson (5min.).

\section{Students should know: [3.4.5.6]}

1. Descriptions of the equipment required for the experiment.

2. The coefficient of internal friction or dynamic viscosity.

3. The causes of the formation of viscosity.

4. Newton's formula.

5. Units of viscosity.

6. Information about Newtonian fluids.

7. Information about non-Newtonian fluids.

8. Blood viscosity and its use in diagnosis.

9. Erythrocyte sedimentation rate (SOE).

10. The use of the coefficient of internal friction in forensic medical examination.

11. Determination of the coefficient of viscosity by the Stokes method.

12. To derive the formula for finding the coefficient of internal friction by the Stokes method.

13. Capillary or Ostvold vskozametrini.

14. Medical or Gess viscometer.

15. Rotational viscometers.

16. Poiseuille formula.

17. Hydraulic resistance.

18. Laminar flow of liquids.

19. Turblent flow of liquids. 
20. Reynolds number.

\section{Additional questions to reinforce the practical lesson: [3.7.8]}

1. What is the "coefficient of internal friction of liquids"?

2. For viscous liquids, write Newton's equation.

3. Explain the temperature dependence of the viscosity coefficient.

4. Newton and Newtonian fluids.

5. Coefficient of viscosity of air, water, glycerin, blood and blood plasma at a temperature of $200 \mathrm{C}$.

6. The importance of the coefficient of internal friction in medicine?

7. Turbulent and laminar flow of fluids.

8. Reynolds number.

9. Viscometers.

10. The effect of viscosity coefficient in medical processes (anesthesia through nay

11. Find the viscosity by the Stokes method.

12. Poiseuille's equation.

13. Hydraulic resistance.

14. Hydraulic resistance when pipes are connected in series.

15. Hydraulic resistance when pipes are connected in parallel.

\section{The module system presents the text of the} practical training on "Determination of the coefficient of internal friction of liquids" (We also abbreviate the text). [2.7.9]

When molecules of real liquids and gases move, internal frictional forces are created because there are mutual gravitational forces between them. These forces occur between the fluid layers, causing anger even if the fluid layers are moving at different speeds. These forces are formed when the velocities of the stratum fluids with high velocities are pulled back by the fluids of the strata with low velocities.

If there is no source that supports the velocities of the fluid layers, the fluid will flow in layers due to the effect of frictional forces and internal friction between the fluid layers.

The first layer is attached to the vessel wall, the velocity is 0 , the second layer is at a low velocity, the third layer is greater, and so on. In the center of the nay, the speed will have a maximum value. Newton found that the frictional force (Ffric) generated between these two layers is proportional to the nature of the fluid, the contact surface (S) of these layers, and the velocity gradient $(\mathrm{dv} / \mathrm{dz})$. Ffric $=$ $\eta \cdot S \cdot d v / d z$ (1) where -S face, $\eta$ - coefficient of friction, $d v / d z$ is the velocity gradient. In the $\mathrm{SI}$ system ${ }^{\wedge}$

In $\mathrm{F} \sim$ Newtons, th is the unit of the coefficient of friction when the th-velocity is measured in $\mathrm{m} / \mathrm{s}$ and the S-surface in $\mathrm{m} 2$.

$\mathrm{N} /\left(\mathrm{m}_{2} \cdot(\mathrm{m} / \mathrm{s}) / \mathrm{m}\right)=\mathrm{N} /(\mathrm{m} 2 \cdot 1 / \mathrm{s})=(\mathrm{N} \cdot \mathrm{s}) / \mathrm{m}$ $=\mathrm{Pa} \cdot \mathrm{s}$.

Represented in Poises in the SGS system

$$
1 \text { puaz }=0,1 \cdot(\mathrm{N} \cdot \mathrm{s}) / \mathrm{m}_{2}=0,1 \mathrm{~Pa} \cdot \mathrm{s} .
$$

1) Liquids whose coefficient of internal friction obeys Newton's law does not depend on the velocity gradient are called Newtonian fluids. Examples are blood plasma water and various solutions.

2) Liquids that do not obey Newton's formula are called non-Newtonian fluids.

Non-Newtonian fluids are liquids composed of large molecules with a complex structure, e.g., 
a solution of polymers. Because blood is composed of shaped elements, the change in velocity gradient does not correspond to the change in the coefficient of internal friction, so blood is a non-Newtonian fluid. The viscosity coefficient of human blood is normal $(4 \div 5)$ $\mathrm{mPa} \cdot \mathrm{s}$, and in pathology it can vary from 1,7 $\mathrm{mPa} \cdot \mathrm{s}$ to $22,9 \mathrm{mPa} \cdot \mathrm{s}$. Determining the coefficient of viscosity of blood is important for diagnosis (diagnostic). If the viscosity decreases in infectious disease, it increases in colds, for example in respiratory diseases. It can also be 22,9 mPa.s in diabetes.

\section{The following additional texts on the topic} "Fluid flow and biophysical properties" are presented in the module system. [2]

1) Stokes' method for finding the "internal friction coefficient of liquids".

2) Find the "viscosity of liquids" with a viscometer.

3) VK-4 (Gess) viscometer.

4) Rotational viscometer.

VI. Advantages of teaching practical lessons in the modular system of the platform SamDTI "zoom" and in the program telegram: $[1,2]$.

1. Students participate in video conferencing in the platform module system and the program "ZOOM", organized by professors and teachers.

2. The student can enter the modular system of the SamDTI platform at any time, independently master the text of the lecture and practice there, and in case of any misunderstandings can easily ask during a video conference.

3. Students have the opportunity to get acquainted with the videos on the topic and the text of additional information on the topic in the modular system of the platform SamMI.

4. Students have the opportunity to strengthen their knowledge by solving tests on the topic, situational tests.

5. The ability of the professor-teacher to control the activity of students on the given topic.

6. The ability of the speaker to control the activity of the student in the modular system of the platform SamMI.

7. Students can find out the questions on the topic in the telegram program and ask the teacher for answers.

\section{REFERENCES}

1. f.-m.f.n., Jalilov M.X. ass. Xamroev J.X., ass. Axrorov M.N. "Improving the quality of modern continuing education: Innovation and prospects" Tashkent 2020. April 24, 431436.

2. mt.sammi.uz. Module 1.Zanyati 2. Theme 7.

3. I.A. Essaulova, M.E.Bloxina, A.D.Gontsov. "Manual for laboratory work in medical and biological physics" Moscow. Vysshaya Shkola 1987. P.94-102.

4. M.Kh.Olmasova, J.A.Tashkhonova, I.Ismoilov, J.Kamolov. "Practicum in Physics" Tashkent "Teacher". 1996 y.

5. M.I.Bazarbaev, X.J.Raximova, F.B.Nurmatova. "Biophysics". Tashkent 2018, pp. 27-35.

6. V.N.Feodrova, E.V.Faustov. "Meditsinskaya i biologicheskaya fizika" kursi leksiy.Moskva.2010, s. 89-163.

7. A.N.Remizov. A.G.Maksina. A.Ya. Potapenko "Meditsinskaya i biologicheskaya fizika" Moskva.2011 yil, s.113-124. 
The American Journal of Medical Sciences and Pharmaceutical Research

(ISSN - 2689-1026)

Published: January 30, 2021 | Pages: 97-101

IMPACT FACTOR

2021: 5.64

Doi: https://doi.org/10.37547/TAJMSPR/Volume03Issue01-15

OCLC - 1121105510

8. S.X.Umarov. "Tibbiyot texnikasi". Toshkent 2012y, 64-92b.

9. A.N.Remizov "Tibbiy va biologik fizika" Toshkent. Ibn Sino nasriety. 1992 y, 161-172b. 